\title{
Phytochemical Analysis and Antioxidant Property of Selected Medicinal Plants Native to Cambodia
}

\author{
Samell Keo ${ }^{1 *}$, Sonita Leang ${ }^{1}$, Chanseiha $\mathrm{Ny}^{1}$, Sokhany Lim ${ }^{1}$, KosalvorlakChean ${ }^{1}$, Huykhim Ung ${ }^{1}$, Juthamart \\ Maneenet $^{2}$, Yaowared Chulikhit ${ }^{2}$ and Sin Chea ${ }^{1}$ \\ ${ }^{1}$ Department of Pharmacy, University of Puthisastra, Cambodia \\ ${ }^{2}$ Department of Pharmaceutical Chemistry, KhonKaen University, Thailand
}

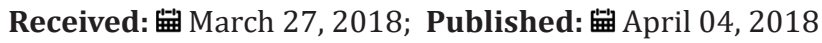

*Corresponding author: Dr. Samell Keo, Pharmacognosy Professor, Department of Pharmacy, University of Puthisastra, Cambodia, Tel: (855)12552681; Email: ksamell@puthisastra.edu.kh

\begin{abstract}
Cambodian medicinal plants have been used to treat different diseases such as cardiovascular diseases, inflammation, cancers, diabetes and AIDS. This study aimed at conducting the Phytochemical analysis and in vitro antioxidant activities of whole plant of Bryophyllumpinnatum (Lam.) Kurz, barks of Dillenia ovata Wall. ex Hook. f. \& Thomson, rhizomes of Drynariafortunei (Kunze ex Mett.) J. Sm. and barks of Lophopetalumwallichii Kurz. native to Cambodia. All the plants were extracted with ethanolby maceration extraction method. The Phytochemical analysis for alkaloids, phenolic compounds, tannins, flavonoids, coumarins, steroids, terpenoids, cardiac glycosides, essential oils, saponins and resins by using the standard methods. The in vitro antioxidant property was evaluated by assessing the $\mathrm{DPPH}^{*}$ radical scavenging ability. The preliminary Phytochemical evaluation of these species exhibited that the ethanolic extracts of B. pinnatum (whole plant), D. ovata (barks), D.fortunei (rhizomes) and L.wallichii (barks) contain alkaloids, phenolic compounds, tannins, flavonoids, terpenoids, cardiac glycosides, saponins and resins. Moreover, the ethanolic extracts of B. pinnatum whole plant, D. ovata barks, and D.fortunei rhizomes possess coumarins and steroids, and of L.wallichii barks have essential oils. The in vitro antioxidant activity of the species B. pinnatum whole plant, D. ovata barks, D.fortunei rhizomes and L.wallichii barks have prominent antioxidant activities. This study suggests the potential source of natural antioxidant in B. pinnatum, D. ovata, D.fortunei and L.wallichii native to Cambodia. Further research is highly recommended on the isolation of the antioxidant compounds from these species.
\end{abstract}

Keywords: B. pinnatum; D. ovate; D. fortune; L.wallichii; Phytochemical analysis; In vitro antioxidant activity

\section{Introduction}

Reactive Oxygen Species (ROS) or free radicals are unstable intermediates formed from molecules via the breakage of a chemical bond such that each fragment keeps one electron, via cleavage of a radical to give another radical and, also via redox reactions [1]. The ROS are categorized into oxygen-centered radicals and oxygen-centered non-radicals. The oxygen-centered radicals include superoxide anion $\left(\bullet \mathrm{O}_{2}^{-}\right)$, hydroxyl radical $(\bullet \mathrm{OH})$, alkoxyl radical (RO•) and peroxyl radical (ROO•), and nitrogen species. The oxygen-centered non-radicals are hydrogen peroxide $\left(\mathrm{H}_{2} \mathrm{O}_{2}\right)$ and singlet oxygen $\left({ }^{1} \mathrm{O}_{2}\right)$, hypochlorous acid $(\mathrm{HClO})$ and ozone $\left(\mathrm{O}_{3}\right)$ [2]. Free radicals are also generated either from normal essential metabolic processes in the human body or from external sources such as exposure to X-rays, ozone, cigarette smoking, air pollutants, and industrial chemicals causing oxidative stress which is able to adversely alter lipids, protein and DNA triggering various human complications such as cancers, atherosclerosis, neurodegenerative diseases, diabetes, age-related eye disease and Parkinson's disease [3].

The free radicals can be scavenged by using the antioxidant system including non-enzymatic constituents and a series of antioxidant enzymes. The non-enzymatic constituents include glutathione, selenium, vitamin $\mathrm{C}$ and $\mathrm{E}$. The antioxidant enzymes embrace glutathione peroxidase, catalase and superoxide dismutase which are the predominant antioxidant enzymes playing a key role in minimizing the oxidative stress [4]. Several studies reported the free radical scavenging activities of medicinal plants 
considered as the natural antioxidant, which is utilized in several medical applications as their assurance of effectiveness and safety [5]. The medicinal plants in form of roots, barks, leaves, seeds and fruits have been used to manage various illnesses since the ancient Cambodian era [6]. Medicinal plants are composed of some bioactive compounds influencing the physiological functions of the human body and these active phyto constituents include alkaloids, terpenes and phenolic compounds [7], biosynthesized by the pathways of acetyl coenzyme A, shikimic acid, mevalonic acid and 1-deoxylulose 5-phosphate in the plant [8]. The Phytochemical is being broadly examined for its ability to provide health benefits, and several reports proved their curative effects on cardiovascular diseases, inflammation, cancers, diabetes and AIDS [9], the underlying mechanism of which is due to their bioactivities as substrates for biochemical reactions, cofactors of enzymatic reactions, and inhibitors of enzymatic reactions [10].

However, no much scientific authentication has been made for most of medicinal plants native to Cambodia. To address this lacuna, the present investigation was carried out for the Phytochemical analysis and in vitro antioxidant activities of whole plant of Bryophyllumpinnatum(Lam.) Kurz (Crassulaceae) (local name: KabelLapoahs), barks of Dillenia ovata Wall. ex Hook. f. \& Thomson (Dilleniaceae) (local name: Phlu Thom), rhizomes of Drynariafortunei (Kunze ex Mett.) J. Sm. (Polypodiaceae) (local name: Baabrak), and barks of Lophopetalumwallichii Kurz (Celastraceae) (local name: Puen Ta Lei) [11].

\section{Material and Methods}

\section{Collection of Plants}

The whole plant of B. pinnatum, the barks of D. ovata, the rhizomes of D.fortunei and the barks of L.wallichiiin the dried form were collected from the local drugstore selling medicinal plants in Phnom Penh, Cambodia, in August 2017. The plants were authenticated with the voucher specimens UPFPT-110071 (B. pinnatum), UPFPT-110057 (D. ovata), UPFPT-110069 (D. fortunei) and UPFPT-110066 (L. wallichii) of University of Puthisastra (UP)Herbarium. The parts of the plant samples were deposited in the UP-Herm barium and the Pharmacognosy Laboratory, Department of Pharmacy, Faculty of Health Sciences, University of Puthisastra, Cambodia, aiming at conducting further investigation.

\section{Preparation of Plant Extracts}

The maceration method was applied to the extraction of the plants. Each plant part was powdered and kept in contact with ethanol in the concentration of $157 \mathrm{~g} / 3500 \mathrm{~mL}$ (B. pinnatum whole plant), $420 \mathrm{~g} / 6100 \mathrm{~mL}$ (D. ovata barks), 192g/3800mL (D.fortunei rhizomes), and $161 \mathrm{~g} / 5600 \mathrm{~mL}$ (L.wallichii barks). The supernatants were collected by filtration after 24 hours, and the solvent was evaporated to make the crude extracts. Each crude extract was subjected to the lyophilisation. The residues obtained were stored in airtight bottles in a refrigerator for the phytochemical evaluation and the in vitro antioxidant activity. The plant extraction was carried out at the Laboratory of Biological Pharmacology, Department of Pharmaceutical Chemistry, Faculty of Pharmaceutical Sciences, KhonKaen University, Thailand.

\section{Phytochemical Analysis}

The ethanolic extracts of B. pinnatum whole plant, D. ovata barks, D.fortunei rhizomes and L.wallichii barks underwent the Phytochemical screening in order to detect the presence or the absence of alkaloids, phenolic compounds, tannins, flavonoids, coumarins, steroids, terpenoids, cardiac glycosides, essential oils, saponins and resins by using the standard methods [12]. This Phytochemical test was evaluated in the Pharmacognosy Laboratory, University of Puthisastra.

Evaluation of Alkaloids (Dragendorff's, Mayer's and Wagner's Tests): The crude extracts were dissolved with $1 \mathrm{M}-\mathrm{HCl}$ $(100 \mathrm{mg} / 10 \mathrm{~mL}$ ) and subjected to the filtration. The filtrate was loaded equally into four test tubes. One control test tube was added with no reagent, and the rest of test tubes were treated with Dragendorff's, Mayer's or Wagner's reagents. The orange red (Dragendorff), creamy white (Mayer) or reddish brown (Wagner) precipitates demonstrated the presence of Alkaloids [13].

Evaluation of Phenolic Compounds (Ferric Chloride Test): the crude extracts were added with ethanol $(100 \mathrm{mg} / 10 \mathrm{~mL})$, and the solution was filtrated. Two-milliliter filtrate was pipetted into the test tube, following with the addition of distilled water $5 \mathrm{~mL}$. Four drops of $5 \%-\mathrm{FeCl}_{3}$ were dripped into the filtrate. The formation of dark green precipitate showed the presence of Phenolic Compounds [14].

Evaluation of Tannins (Ferric Chloride Test): The ethanol was added to the crude extract $(100 \mathrm{mg} / 10 \mathrm{~mL})$, and the mixture was filtrated. The two-milliliter filtrate was transferred into the test tube and added with few drops of $0.1 \%-\mathrm{FeCl}_{3}$. The tested group was compared with the control group, which was not added with the reagent. The brownish green coloration interpreted the presence of Tannins [15].

Evaluation of Flavonoids (Ammonium Test): The crude extracts were dissolved in chloroform $2 \mathrm{~mL}$ and taken into the test tube. One milliliter of $1 \%-\mathrm{NH}_{4}$ was added into it. The mixture was shaken vigorously. The yellow color observed in the ammonia layer demonstrated the presence of Flavonoids [16].

Evaluation of Coumarins (NaOH Test): the crude extracts with the addition of ethanol in the concentration of $100 \mathrm{mg} / 10 \mathrm{~mL}$ were filtrated. The two-milliliter of filtrate was loaded into the test tube and added with $3 \mathrm{~mL}$ of $10 \%-\mathrm{NaOH}$. The yellow coloration represented the presence of Coumarins [17].

Evaluation of Steroids (Liebermann-Burchard Test): The crude extract $100 \mathrm{mg}$ was dissolved in the chloroform $2 \mathrm{~mL}$ 
and filtered into the test tube. The mixture was added with $1 \mathrm{~mL}$ of glacial acetic acid, followed by carefully the addition of $1 \mathrm{ml}$ of $\mathrm{H}_{2} \mathrm{SO}_{4}$ along the side of the test tube. The greenish color indicated the presence of Steroids [18].

Evaluation of Terpenoids (Salkowski's Test): The crude extract of $100 \mathrm{mg}$ was dissolved in the chloroform $5 \mathrm{~mL}$ and filtered into the test tube. The mixture was added carefully with $3 \mathrm{~mL}$ of $\mathrm{H}_{2} \mathrm{SO}_{4}$ along the side of the test tube. The reddish brown color at the interface of the two phases characterized the presence of Terpenoids [19].

Evaluation of Cardiac Glycosides (Keller-Kiliani's Test): The glacial acetic acid $2 \mathrm{~mL}$ was mixed with 2 drops of $2 \%-\mathrm{FeCl}_{3}$. The crude extract $100 \mathrm{mg}$ was dissolved in this solution in the test tube. The mixture was added with $1 \mathrm{~mL}$ of $\mathrm{H}_{2} \mathrm{SO}_{4}$ along the side of the test tube. The brown ring at the interface indicated the presence of Cardenolides, and the violet-green ring below the brown ring in the acetic acid layer represented Glycoside. These together characterized Cardiac Glycosides [19,20].

Evaluation of Essential Oils ( $\mathrm{NaOH}-\mathrm{HCl}$ Test): In the test tube, the filtrate $2 \mathrm{~mL}$ of the extract was added with $100 \mu \mathrm{l}$ of $1 \mathrm{M}-\mathrm{NaOH}$, followed by the addition of 3 drops of $1 \mathrm{M}-\mathrm{HCl}$. The mixture was shaken. The white precipitate demonstrated the presence of Essential Oils [21].

Evaluation of Saponins (Froth Test): the distilled water 15mL were added to $100 \mathrm{mg}$ of the crude extract and filtered into the test tube. The mixture was shaken for $10 \mathrm{~min}$ until the formation of stable persistent froth. Formation of stables five-minute persistent froth indicated the presence of Saponins [22].

Evaluation of Resins (Turbidity Test): Ten milliliter of distilled water were added to $200 \mathrm{mg}$ of the crude extract and filtered into the test tube, and the mixture was observed. The occurrence of turbidity showed the presence of Resins [21].

DPPH ${ }^{*}$ Radical Scavenging Assay: 1, 1-diphenyl-2picrylhydrazyl (DPPH) radical scavenging method is a rapid and sensitive procedure to observe the antioxidant activity of plant extracts. The stock solutions of the extracts were prepared in ethanol to achieve the concentration of $1 \mathrm{mg} / \mathrm{ml}$. The dilutions were made to obtain the concentrations of $100,250,500,750$ and $1000 \mu \mathrm{g} / \mathrm{mL}$ (B. pinnatum whole plant); 2, 4, 6, 8 and $10 \mu \mathrm{g} /$ $\mathrm{mL}$ (D. ovata barks); 150, 200, 250, 300 and 350 $\mathrm{g} / \mathrm{mL}$ (D.fortunei rhizomes); and 20, 30, 40, 50 and $60 \mu \mathrm{g} / \mathrm{mL}$ (L.wallichii barks).The diluted solutions $(100 \mu \mathrm{L}$ each) were mixed with $100 \mu \mathrm{L}$ of ethanolic solution of DPPH $(200 \mu \mathrm{M})$. The mixture was left for 30min in the darkness at room temperature, and the absorbance was recorded at $550 \mathrm{~nm}$. The experiment was replicated in three independent assays. The solution without samples and with DPPH and ethanol was used as negative control, and the Trolox $(30 \mu \mathrm{M})$ was used as a positive control. The inhibition of DPPH free radical in percentage was calculated by the formula:

$$
\text { Inhibition }(\%)=\left[\left(\mathrm{A}_{\text {negative control }}-\mathrm{A}_{\text {test }}\right) /\left(\mathrm{A}_{\text {negative control }}-\mathrm{A}_{\text {control }}\right)\right]
$$
$\mathrm{x} 100$

Where $\mathrm{A}_{\text {negative control }}$ is the absorbance of the negative control $(\mathrm{DPPH}+\mathrm{EtOH})$ and $\mathrm{A}_{\text {test }}$ is the absorbance of sample extracts. A control is the absorbance of the control (Et OH alone). All tests were run in triplicates $(n=3)$, and average values were calculated [23]. The assay was carried out in the Laboratory of Biological Pharmacology, KhonKaen University. The $\mathrm{IC}_{50}$ parameter was used for the interpretation of the results from DPPH method. The discoloration of sample was plotted against the sample concentration in order to calculate the $\mathrm{IC}_{50}$ value. It is defined as the amount of sample necessary to decrease the absorbance of DPPH by $50 \%$ [23].

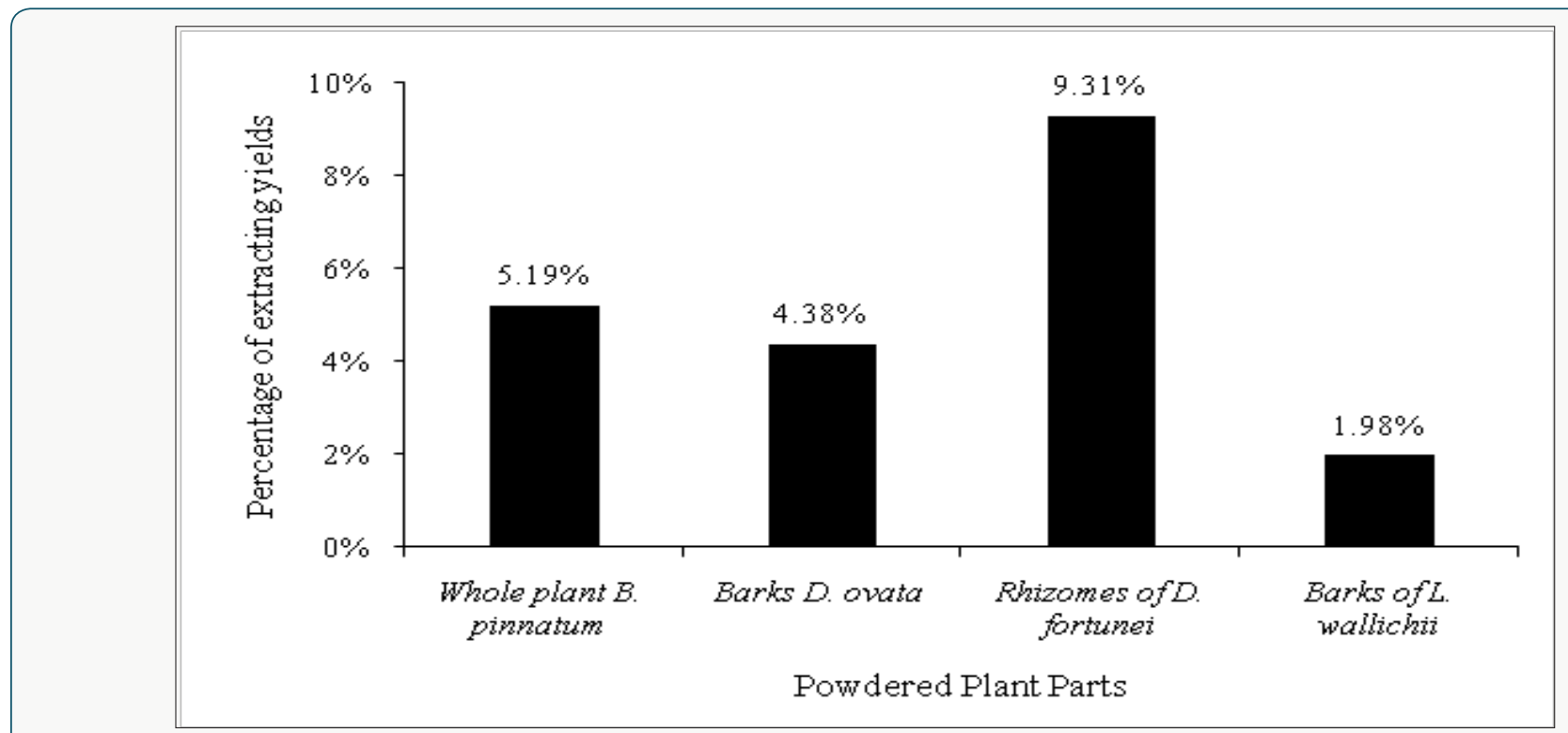

Figure 1: Ethanolic extracting yields (\%) of four plant parts. 


\section{Results and Discussion}

\section{Extracting Yields (\%) of Powdered Plants}

The present study revealed that the ethanolic extracting yield of D. fortunei rhizomes (9.31\%) showed the highest value, following by the yields of $B$. pinnatum whole plant $(5.19 \%)$, D. ovata barks (4.38\%) and L.wallichii barks (1.98\%) successively (Figure 1). The maceration method is considered as one of the general techniques of medicinal plant extraction, and ethanol is widely used as a solvent to extract the plant-derived chemicals [24]. Several reports showed the different extracting values of different Cambodian plant extracts $[25,26]$, which is in consistence with our study indicating different percentages of extracting yield. The technique of maceration extraction is commonly used at the drug manufacturing enterprise line [27].

\section{Preliminary Phytochemical Evaluation}

The current study indicated that the ethanolic extracts of B. pinnatum whole plant, D. ovata barks, D. fortune rhizomes contained alkaloids, phenolic compounds, tannins, flavonoids, coumarins, steroids, terpenoids, cardiac glycosides, saponins and resins, but showed the negative test of essential oils. The ethanolic extract of L. wallichii barks demonstrated the positive tests of alkaloids, phenolic compounds, tannins, flavonoids, terpenoids, cardiac glycosides, essential oils, saponins and resins; however, the coumarins and the steroids were not positively tested (Table 1). Phytochemical are secondary metabolites that enable plants to overcome temporary or continuous threats integral to their environment, which is beneficial to the human in term of medical treatment [28]. The plant-derived anticancerous drugs such asetoposide and taxol have been applied for years in the clinical use and play a crucial role in the development of the novel drug entities for human [29]. The medicinal plants contributing towards the ethnomidicine have been broadly screened for their PhytochemicalS including alkaloids, tannins, saponins, steroid, terpenoid, flavonoids, phlobatannin and cardic glycoside [30].They are associated with protection from and/or treatment of chronic diseases such as heart disease, cancers, diabetes, and hypertension as well as other medical conditions [31].

Table 1: Phytochemical screening of the ethanolic extracts of B. pinnatum whole plant, D. ovata barks, D. fortune rhizomes and L. wallichii barks.

\begin{tabular}{|c|c|c|c|c|c|}
\hline Phytochemicals & Types of Tests & $\begin{array}{c}\text { Whole plant of } B . \\
\text { pinnatum }\end{array}$ & Barks of D. ovata & $\begin{array}{l}\text { Rhizomes of } D . \\
\quad \text { fortunei }\end{array}$ & Barks of L. wallichii \\
\hline \multirow[t]{3}{*}{ Alkaloids } & Dragendorff & $+\mathrm{ve}$ & $+\mathrm{ve}$ & $+\mathrm{ve}$ & $+\mathrm{ve}$ \\
\hline & Mayer & $+\mathrm{ve}$ & $+\mathrm{ve}$ & $+\mathrm{ve}$ & $+\mathrm{ve}$ \\
\hline & Wagner & $+\mathrm{ve}$ & $+\mathrm{ve}$ & $+\mathrm{ve}$ & $+\mathrm{ve}$ \\
\hline Phenolic compounds & Ferric chloride & $+\mathrm{ve}$ & $+\mathrm{ve}$ & $+\mathrm{ve}$ & $+\mathrm{ve}$ \\
\hline Tannins & Ferric chloride & $+\mathrm{ve}$ & +ve & $+v e$ & $+v e$ \\
\hline Flavonoids & Ammonium & $+\mathrm{ve}$ & $+\mathrm{ve}$ & $+\mathrm{ve}$ & $+\mathrm{ve}$ \\
\hline Coumarins & $\mathrm{NaOH}$ & $+\mathrm{ve}$ & $+v e$ & $+\mathrm{ve}$ & -ve \\
\hline Steroids & Liebermann-Burchard & +ve & $+\mathrm{ve}$ & $+\mathrm{ve}$ & -ve \\
\hline Terpenoids & Salkowski & $+\mathrm{ve}$ & $+\mathrm{ve}$ & $+\mathrm{ve}$ & $+\mathrm{ve}$ \\
\hline Cardiac glycosides & Keller-Kiliani & $+\mathrm{ve}$ & $+v e$ & $+v e$ & $+v e$ \\
\hline Essential oils & $\mathrm{NaOH}-\mathrm{HCl}$ & -ve & -ve & -ve & $+v e$ \\
\hline Saponins & Froth & $+\mathrm{ve}$ & $+\mathrm{ve}$ & $+\mathrm{ve}$ & $+\mathrm{ve}$ \\
\hline Resins & Turbidity & +ve & $+v e$ & $+v e$ & $+v e$ \\
\hline
\end{tabular}

Note: + ve $=$ Positive $($ present); - ve = Negative (absent)

\section{DPPH Radical Scavenging Activity}

The free radical scavenging activity of the ethanolic extract of different plants was tested by DPPH radical method using Trolox as a positive control. The DPPH assay provides information on the reactivity of the test extracts with a stable free radical giving an absorption band at $550 \mathrm{~nm}$ [32]. The concentration of B. pinnatum whole plant ranged from $100-1000 \mu \mathrm{g} / \mathrm{mL}$, of D. ovata barks ranged from $2-10 \mu \mathrm{g} / \mathrm{mL}$, of D. fortunei rhizomes ranged from $150-350 \mu \mathrm{g} /$ $\mathrm{mL}$, and of L.wallichii barks ranged from $20-60 \mu \mathrm{g} / \mathrm{mL}$. The ethanolic extract of $B$. pinnatum whole plant inhibited the free radical in dosedependent manner $(\mathrm{R} 2=0.9068)$ with the inhibition percentage $17.72,39.69,65.35,83.31$ and $84.57 \%$ at the concentration of
$100,250,500,750$ and $1000 \mu \mathrm{g} / \mathrm{mL}$ respectively (Figure 2). The ethanolic extract of $D$. ovata barks inhibited the free radical in dosedependent manner (R2=0.9361)with the inhibition percentage $14.23,32.77,59.07,60.35$ and $75.06 \%$ at the concentration of $2,4,6,8$ and $10 \mu \mathrm{g} / \mathrm{mL}$ respectively (Figure 3 ). The ethanolic extract of $\mathrm{D}$. fortunei rhizomes inhibited the free radical in dose-dependent manner $(\mathrm{R} 2=0.991)$ with the inhibition percentage 28.58, 34.6, $44.41,50.36$ and $56.23 \%$ at the concentration of $150,200,250,300$ and $350 \mu \mathrm{g} / \mathrm{mL}$ respectively (Figure 4 ). The ethanolic extract of L. wallichii barks inhibited the free radical in dose-dependent manner $(\mathrm{R} 2=0.9648)$ with the inhibition percentage 27.41, 53.28, 60.21, 75.53 and $87.32 \%$ at the concentration of $20,30,40,50$ and $60 \mu \mathrm{g} /$ 
$\mathrm{mL}$ respectively (Figure 5). The IC50 of the ethanolic extracts of $B$. pinnatum whole plant, D. ovata barks, D. fortunei rhizomes and L.

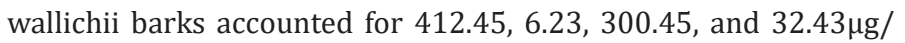
$\mathrm{mL}$ respectively (Table 2 ). Several studies reported the free radical scavenging potential of medicinal plant extracts [33-35]. The antioxidant plant drugs play an important role in the prevention and treatment of various disorders, caused by oxidative stress, such as cancers, cardiovascular diseases, diabetes mellitus, obesity and neurodegenerative diseases [36].

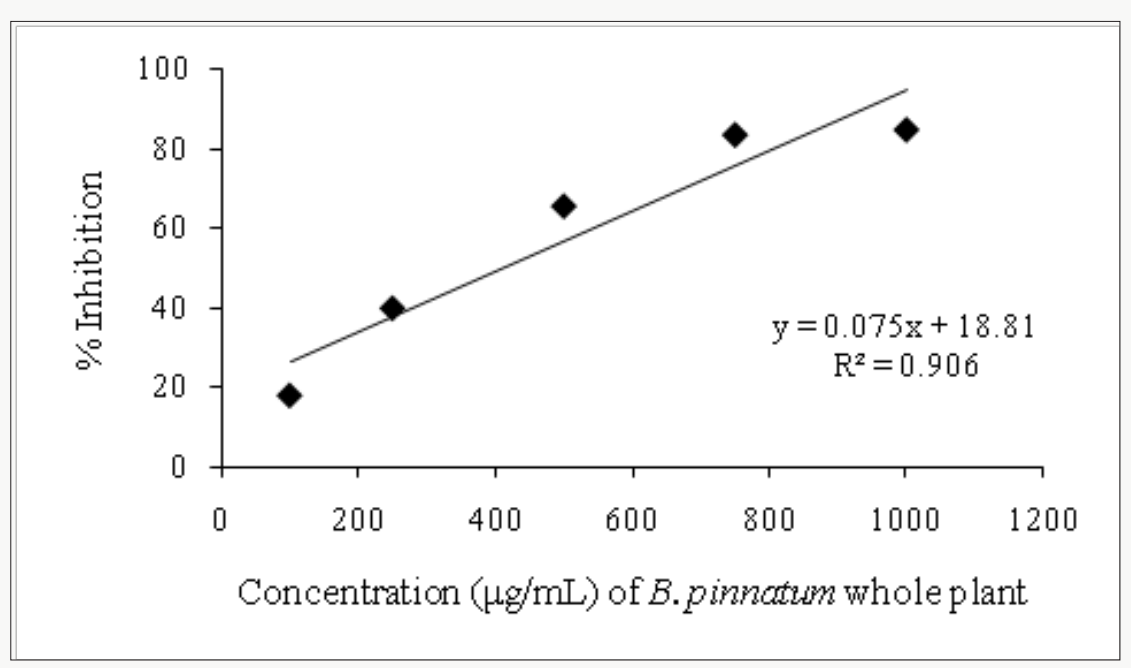

Figure 2: Free radical scavenging activity of ethanolic extrat of B. pinnatum whole plant.

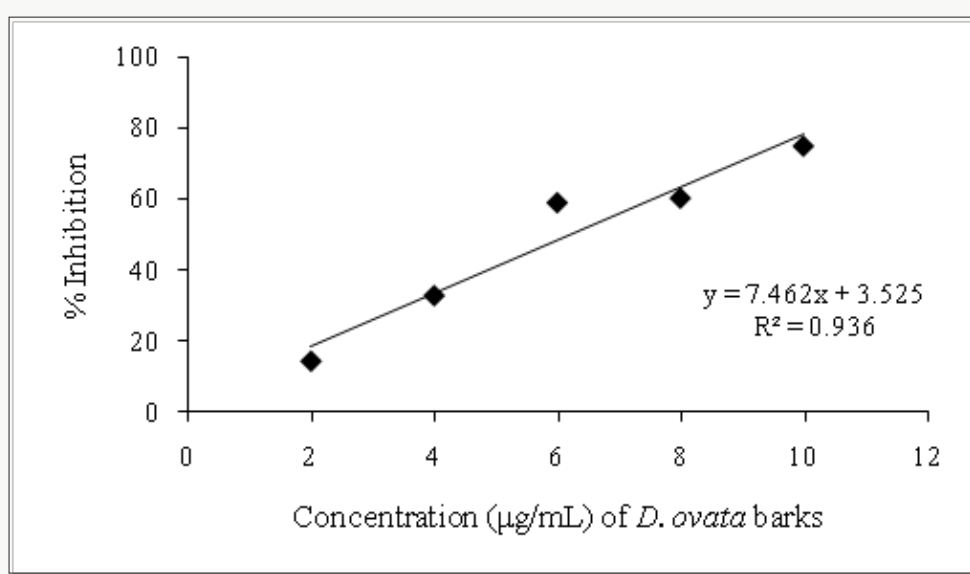

Figure 3: Free radical scavenging activity of ethanolic extrat of D. ovata barks.

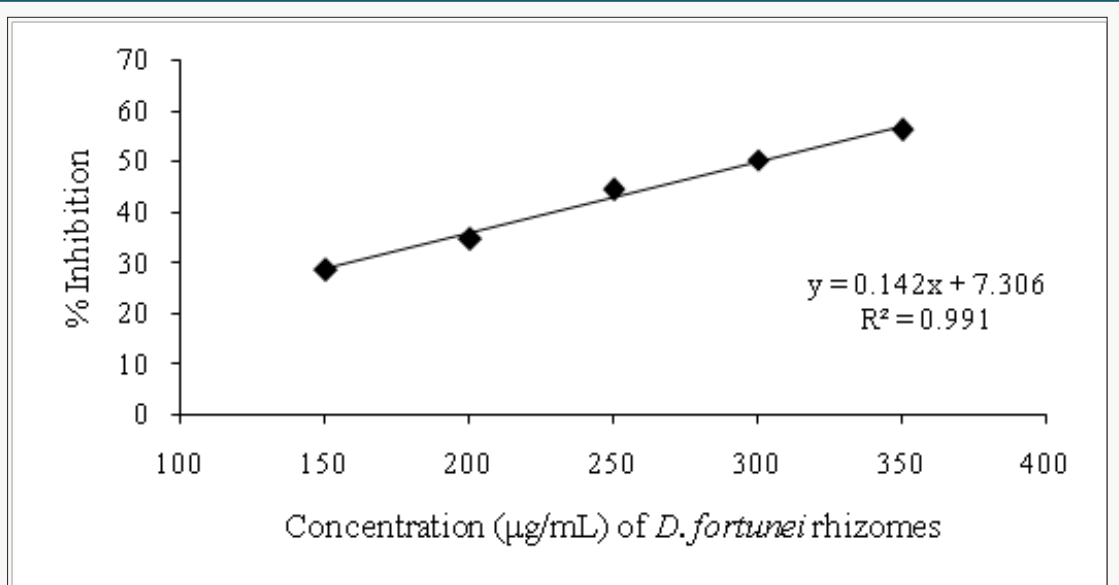

Figure 4: Figure 4: Free radical scavenging activity of ethanolic extrat of $D$. fortunei rhizomes 


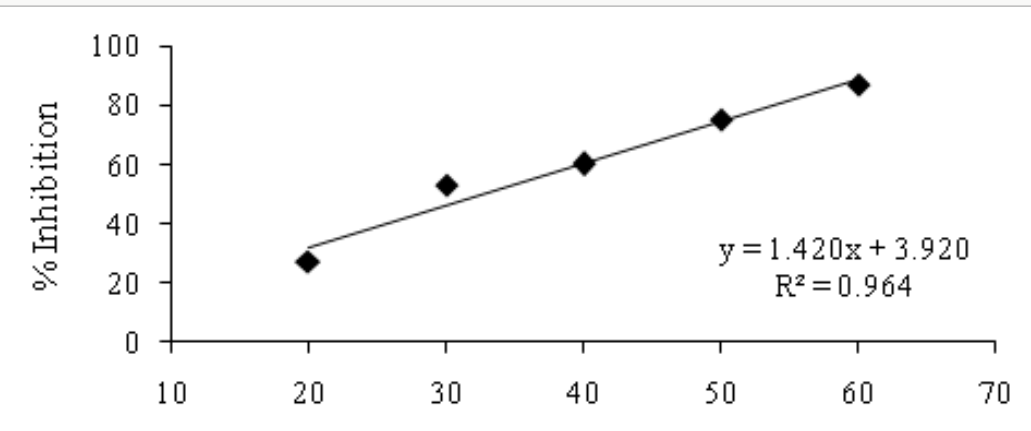

Concentration $(\mu g / \mathrm{mL})$ of L. wallichii barks

Figure 5: Free radical scavenging activity of ethanolic extrat of L. wallichii barks.

Table 2: Inhibition Concentration (IC50) of the selected medicinal plants.

\begin{tabular}{|c|c|c|c|}
\hline Medicinal Plants & Khmer Names & Plant Parts & IC $_{\mathbf{5 0}}(\boldsymbol{\mu g} / \mathbf{m L})$ \\
\hline B. pinnatum & KabelLapoahs & Whole plant & 412.45 \\
\hline D. ovata & Phlu Thom & Barks & 6.23 \\
\hline D.fortunei & Baabrak & Rhizomes & 300.45 \\
\hline L.wallichii & Puen Ta Lei & Barks & 32.43 \\
\hline
\end{tabular}

\section{Conclusion}

The preliminary phytochemical evaluation of these species exhibited that the ethanolic extracts of B. pinnatum (whole plant), $D$. ovata (barks), D. fortunei (rhizomes) and L.wallichii (barks) contain alkaloids, phenolic compounds, tannins, flavonoids, terpenoids, cardiac glycosides, saponins and resins. Moreover, the ethanolic extracts of B. pinnatum whole plant, D. ovata barks, and D.fortunei rhizomes possess coumarins and steroids, and of L.wallichii barks have essential oils. The in vitro antioxidant activity of the species B. pinnatum whole plant, D. ovata barks, D. fortunei rhizomes and L.wallichii barks have prominent antioxidant activities. This study suggests the potential source of natural antioxidant in B. pinnatum, D. ovata, D. fortunei and L.wallichii native to Cambodia. Further research is highly recommended on the isolation of the antioxidant compounds from these species.

\section{Acknowledgment}

This research was supported by the Pharmacognostical Research Project [UPKKUPNRP003] which was approved by the steering committee of the University of Puthisastra. We are tremendously grateful to the management team of the University of Puthisastra for providing us the opportunity to conduct this research. Thanks are due to the staff of the UP-Herbarium for assistance in the identification of the plants. We thank the Department of Pharmacy, Faculty of Health Sciences, University of Puthisastra, for the approval to conduct this study. We also offer thanks to the management team and all professors for providing us with the space to conduct some parts of the research in the Faculty of Pharmaceutical Sciences, KhonKaen University.

\section{References}

1. Pham Huy LA, He H, Pham Huy C (2008) Free radicals, antioxidants in disease and health. International Journal of Biomedical Science 4(2): 8996.

2. Sisein EA (2014) Biochemistry of free radicals and antioxidants. Scholars Academic Journal of Biosciences 2(2): 110-118.

3. Lobo V, Patil A, Phatak A, Chandra N (2010) Free radicals, antioxidants and functional foods: impact on human health. Pharmacognosy Review 4(8): 118-126.

4. El Bahr SM (2013) Biochemistry of free radicals and oxidative stress. Science International 1(5): 111-117.

5. Al Snafi AE (2016) Medicinal plants with antioxidant and free radical scavenging effects (part 2): plant based review. IOSR Journal of Pharmacy 6(7): 62-82.

6. Ka S, Ka M, Ka N, Chhuor (2015) Cambodia: medical anthropology. Anthropology 3(2): 1-4.

7. Kennedy DO, Wightman EL (2011) Herbal extracts and Phytochemical: plant secondary metabolites and the enhancement of human brain function. Advances in Nutrition 2(1): 32-50.

8. Kabera JN, Semana E, Mussa AR, He X (2014) Plant secondary metabolites: biosynthesis, classification, function and pharmacological properties. Journal of Pharmacy and Pharmacology 2(7): 377-392.

9. Saxena M, Saxena J, Nema R, Singh D, Gupta A (2013) Photochemistry of medicinal plants. Journal of Pharmacognosy and Phytochemistry 1(6): 168-182.

10. Dillard CJ, German JB (2000) Phytochemicals: nutraceuticals and human health. Journal of the Science of Food and Agriculture 80(12): 17441756.

11. Kham L (2004) Medicinal plants of Cambodia: habitat, chemical constituents and ethno botanical uses. Bendigo Scientific Press, Golden Square, Australia. 
12. Harborne JB (1984) phytochemical methods: a guide to modern techniques of plant analysis. Chapman and Hall Ltd., London.

13. Humayun S, Ibrar M, Barkatullah, Ahmad I (2012) Comparison of three extracts of Fumeria indica for the evaluation of cytotoxic and phytotoxic activities. International Journal of Biosciences 2(12): 112-119.

14. Raaman N (2006) Phytochemical techniques. New India Publishing, New Delhi.

15. Karthishwaran K, Mirunalimni S, Dhamodharan G, Krishnaveni M and arulmozhi V (2010) Phytochemical investigation of methanolic extract of the leaves of Pergulariadaemia. Journal of Biological Sciences 10(3): 242-246.

16. Sheel R, Nisha K, Kumar J (2014) Preliminary phytochemical screening of methanolic extract of Clerodendroniinfortunalum. IOSR Journal of Applied Chemistry 7(1): 10-13.

17. Sawant RS, Godghate AG (2013) Qualitative phytochemical screening of rhizomes of Curcuma longa Linn. International Journal of Science. Environment and Technology 2(4): 634-641.

18. Bargah RK (2015) Preliminary test of phytochemical screening of crude ethanolic and aqueous extract of Moringapterygsperma Gaertn. Journal of Pharmacognosy and Phytochemistry 4(1): 07-09.

19. Ajiboye BO, Ibkun EO, Edobor G, Ojo AO, Onikanni SA (2013) Qualitative and quantitative analysis of phytochemicals in Senecionbiafrae leaf. International Journal of Invention and Pharmaceutical Sciences 1(5): 428-432.

20. Jaradat N, Hussen F, Ali AA (2015) Preliminary phytochemical screening quantitative estimation of total flavonoids, total phenols and antioxidant activity of Ephedra alata Dencne. Journal of Materials and Environmental Science 6(6): 1771-1778

21. Mir SA, Mishra AK, Reshi ZA, Sharma MP (2013) Preliminary phytochemical screening of some pteridophytes from District Shopian (J \& K). International Journal of Pharmacy and Pharmaceutical Sciences 5(4): 632-637.

22. Djaafar Z, Ridha OM (2014) Phytochemical study of selected medicinal plant, Solanumnigrum, the Algerian Dessert. International Letters of Chemistry, Physics and Astronomy 1: 25-30.

23. Soni A, Sosa S (2013) Phytochemical analysis and free radical scavenging potential of herbal and medicinal plant extracts. Journal of Pharmacognosy and Phytochemistry 2(4): 22-29.

24. Tiwari P, Kumar B, Kaur M, Kaur G, Kaur H (2011) Phytochemical screening and extraction: a review. International Pharmaceutica Sciencia 1(1): 98-106.
25. Oeung S, Nov V, Ung H, Roum K, Yin V, et al. (2017) Phytochemical analysis of different extracts of leaves of Nicotianatabacum L. of Cambodia. Asian Journal of Pharmacognosy 1(3): 18-26.

26. Nov V, Oeung S, Ung H, Roum K, Yin V, et al. (2017) Organoleptic and phytochemical evaluation of different extracts of Vernoniacinerea L. whole plant of Cambodia. Asian Pharm NET 2017Kuala Lumpur, Malaysia.

27. Azwanida NN (2015) A review on the extraction methods use in medicinal plants, principle, strength and limitation. Medicinal \& Aromatic Plants 4:3.

28. Molyneux RJ, Lee ST, Gardner DR, Panter KE, James LF (2007) Phytochemicals: the good, the bad and the ugly? Phytochemistry 68(2224): 2973-2985.

29. Phillipson JD (2001) Phytochemistry and medicinal plants. Phytochemistry 56(3): 237-243.

30. Edeoga HO, Okwu DE, Mbaebie BO (2005) Phytochemical constituents of some Nigerian medicinal plants. African Journal of Biotechnology 4(7): 685-688.

31. Craig WJ (1997) Phytochemicals: guardians of our health. Journal of the American Diabetic Association 97(10): 199-204.

32. Rao DB, Rao PK, Sumitra DJ, Rao TR (2011) Phytochemical screening and antioxidant evaluation of some Indian medicinal plants. Journal of Pharmacy Research 4(7): 2082-2084.

33. Senguttuvan J, Paulsamy S, Karthika K (2014) Phytochemical analysis and evaluation of leaf and root parts of the medicinal herb, Hypochaerisradicata L. for in-vitro antioxidant activities. Asian Pacific Journal of Tropical Biomedicine 4(1): S359-S367.

34. Dluya T, Daniel D, Yusuf U (2017) In-vitro antioxidant activity and phytochemical evaluation of five medicinal plants extract. The Pharmaceutical and Chemical Journal 4(5): 73-82.

35. Chandra S, Saklani S, Mishra AP, Agrawal RK (2016) In-vitro antioxidant activity and phytochemical screening of Garhwal Himalaya medicinal plants. International Journal of Medical Research \& Health Sciences 5(8): 35-43.

36. Zhang Y, Gan R, Li S, Zhou Y, Li A, et al. (2015) Antioxidant phytochemicals for the prevention and treatment of chronic diseases. Molecules 20(12): 21138-21156

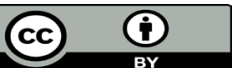

This work is licensed under Creative Commons Attribution 4.0 License

Submission Link:

Submit Article

DOI: 10.32474/DDIPIJ.2018.01.000109

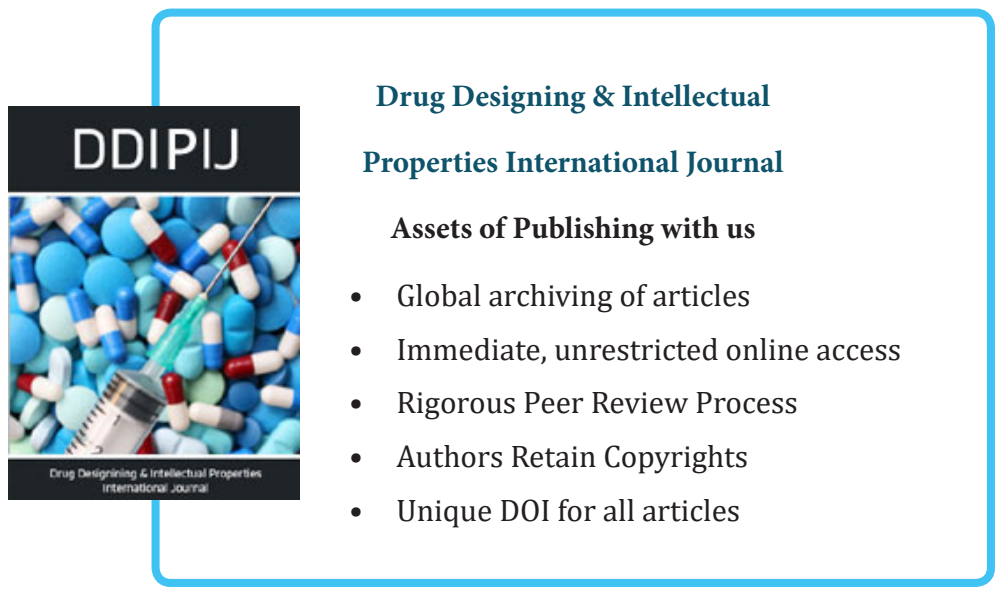

